\title{
Gestão estratégica no Poder Legislativo: o caso da Câmara dos Deputados
}

André Sathler Guimarães, Fabiano Peruzzo Schwarts, Juliana Werneck de Souza, Maria Raquel Mesquita Melo e Rogério Ventura Teixeira

\section{Introdução}

As ações do setor público devem responder e antecipar as demandas dos cidadãos. Além disso, devem se sujeitar ao controle social, o que significa uma prestação de contas abrangente, não apenas do que é feito, mas de como é feito, por que é feito e para quem é feito. A partir dessas premissas, a busca por uma gestão estratégica incorporou-se às propostas de diversos órgãos do setor público. A formulação estratégica ganhou relevância quando os governos passaram a lidar com descontinuidades ambientais. Em ambientes de intensas mudanças, a estratégia deve ser cada vez mais dinâmica, centrando sua força na capacidade de prever e reagir aos movimentos e contramovimentos da conjuntura.

O presente artigo tem como objetivo registrar, criticamente, o processo de implantação do planejamento e gestão estratégica na Câmara dos Deputados. O propósito é descrever analiticamente o processo, a fim de revelar seus antecedentes e motivações; os momentos-chave; as facilidades e dificuldades; os resultados 
até aqui alcançados e os desafios futuros. A gestão estratégica em órgãos do Poder Legislativo é ainda incipiente, no Brasil e no mundo, o que agrega relevância ao presente estudo. A abordagem escolhida foi a da pesquisa histórico-descritiva, entendida como processo metodológico adequado para uma pesquisa focada no "como", além de tratar de fenômeno contemporâneo e não totalmente estudado. As ações de pesquisa envolveram revisão bibliográfica, pesquisa documental ${ }^{1}$ e entrevistas semiestruturadas com protagonistas do processo de decisão e implantação da gestão estratégica na Câmara dos Deputados ${ }^{2}$. O objetivo das entrevistas qualitativas foi compreender as crenças, atitudes, valores e motivações dos servidores em relação ao processo de implantação da gestão estratégica na Câmara, ou seja, propiciar a criação de um quadro interpretativo quanto às relações entre esses atores, na situação social específica de servidores dessa casa legislativa (cf. BAUER \& GASKell, 2008, p.65).

Copeland e Patterson (1997) chamam a atenção para o fato de que, apesar de sua importância no contexto institucional, os parlamentos são pouco estudados. Esse fato, associado às mudanças no cenário ambiental - brevemente delineadas anteriormente -, dão relevância a estudos como o proposto, sobre as iniciativas da administração pública legislativa em busca de maior eficácia para suas ações.

\section{Administração pública e gestão estratégica: fundamentação teórica}

A pesquisa partiu da necessidade de enquadrar a Câmara dos Deputados na literatura sobre gestão pública. Integrante do "núcleo estratégico" do Estado (BRASIL, 1995), a Câmara dos Deputados tem o perfil clássico de uma organização do setor público, o qual se baseia fortemente nos conceitos weberianos (WEBER, 2000) e nas premissas da administração clássica (TAYlor, 2010; Fayol, 2010). Tomando-se como referência a tipologia desenvolvida por Mintzberg (2003) ${ }^{3}$, a Câmara dos Deputados pode ser classificada como uma "burocracia mecanizada", entre as cinco possibilidades descritas por aquele autor. Guarda essa classificação estreita relação com o paradigma clássico da administração, além de agregar elementos importantes à análise.

Os autores trabalharam, ainda, com as obras de Porter (1986, 1989, 1999, 1999a, 1999b), Mintzberg (2010) e Besanko et. alli (2006), sobre o tema da gestão estratégica. A quintessência do pensamento de Porter afirma que estratégia é a criação de uma posição exclusiva (uma proposta de valor diferenciada que atenda às necessidades do público-alvo). $\mathrm{Na}$ radicalidade da proposta de Porter, o que não atender a esse critério não passa de melhorias operacionais. Essa tensão está presente no caso da Câmara dos Deputados e manifesta-se particularmente na decisão do corpo administrativo da Câmara, capitaneada pela Diretoria-Geral, de se realizar um planejamento estratégico restrito à área de apoio técnico-administrativo e legislativo.

Evidentemente, a aplicação no setor público dos conceitos e instrumentos da administração estratégica, originalmente pensados para o setor privado, requer mediação e cuidado. A ênfase do trabalho de Porter, por exemplo, é a estratégia "competitiva", ou seja, aquela que se adota diante de competidores em uma determinada arena. Não por acaso, Porter é considerado um dos pais da Escola de Posicionamento (MintzBerg, 2010). Essa dimensão não se aplica diretamente ao contexto da Câmara dos Deputados - ou a 
qualquer outra instituição do Poder Legislativo -, que se insere em um quadro institucional diferenciado. Ocorre que, durante o trabalho, foi apontada como antecedente a experiência do Gespública, por sua vez inspirada nos postulados da administração pública gerencial ${ }^{4}$. A proposta básica da administração pública gerencial é emprestar conceitos e práticas de sucesso no âmbito da gestão das empresas privadas, sem perder a característica específica da administração governamental, que tem o interesse público como seu elemento finalístico.

Dada essa ligação, os autores trabalharam também, em seu referencial teórico, com obras de Osborne e Gaebler (1995), Lane (2001) e Barzelay (2001). Isso não significa uma aceitação acrítica dos postulados da administração pública gerencial. Ressalte-se que o caráter descritivo da pesquisa leva à análise do fenômeno existente, sem entrar no mérito, a priori, da validade de sua existência.

Tendo em vista que a metodologia de gestão estratégica adotada pela Câmara dos Deputados foi a do Balanced Scorecard (BSC), os autores utilizaram obras de Kaplan e Norton (1996, 2004, 2006, 2008). Kaplan e Norton (2004) explicitam que seu trabalho é baseado no modelo de estratégia de Porter, e propõem o BSC como instrumento de medição dos parâmetros críticos de geração de valor em longo prazo.

\section{Gestão estratégica na Câmara dos Deputados: antecedentes e motivações}

A pesquisa documental e as entrevistas revelaram, como antecedentes importantes ao processo de implantação da gestão estratégica na Câmara dos Deputados, a realização de diversos cursos de capacitação. Os cursos propiciaram, segundo dados das entrevistas, o surgimento de uma "massa crítica" de pessoas conscientes quanto ao tema estratégia, fator importante tanto como estímulo ao início do movimento quanto como facilitador da implantação.

Em 2001, houve ampla mudança na cúpula administrativa da Câmara, assumindo postos-chave servidores que tinham postura aberta às questões de estratégia,

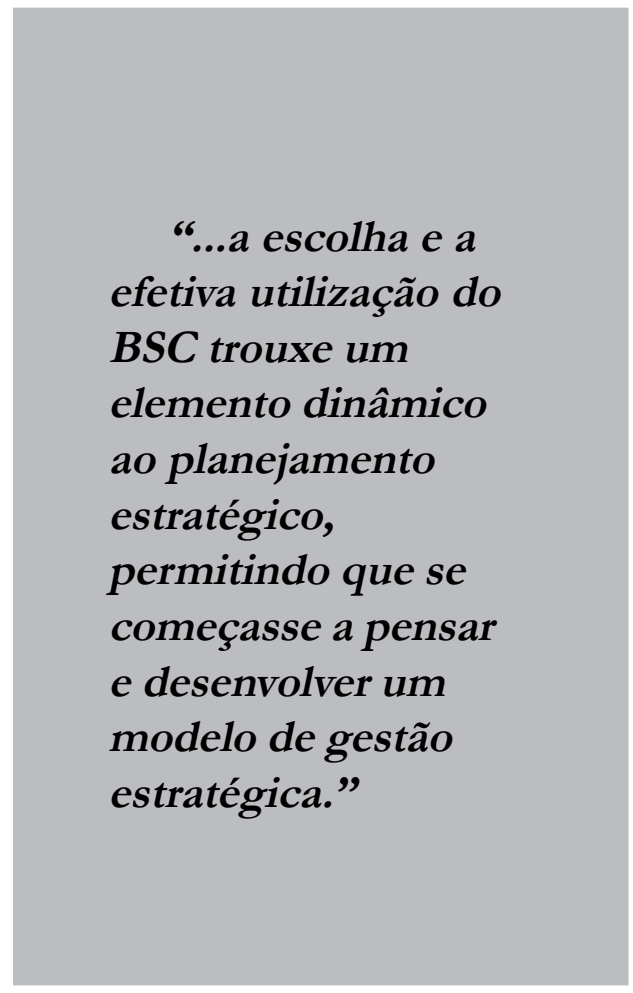

alguns deles participantes dos cursos citados. Logo em 2002, foi criada a Assessoria de Projetos Especiais ${ }^{5}$, que teria, entre suas atribuições, a de pensar questões estratégicas para a instituição. Ainda como parte do processo de transição entre gestões, foi criado um grupo de trabalho para adotar as providências necessárias à implantação do processo de planejamento estratégico na Câmara dos Deputados ${ }^{6}$, que 
teve, entre suas atribuições, a de refletir e propor critérios para tomada de decisão com relação a pedidos de mudança na estrutura organizacional.

Houve iniciativas isoladas e independentes de planejamento estratégico em setores da Câmara, como o Centro de Informática e a Consultoria Legislativa. Ambos foram processos autocentrados e conduzidos de forma isolada, não tendo, portanto, desdobramentos mais amplos ${ }^{7}$. Apesar disso, esses processos também foram importantes, por sensibilizar e deixar marcas nos participantes, que viriam a ocupar postos de direção no órgão. Confirmando essa percepção, destaca-se trecho do documento "Diretrizes Estratégicas para a Gestão da Câmara dos Deputados"8:

Constatam-se já iniciativas relevantes, muitas das quais surgidas isolada e espontaneamente. Isso indica que o momento é propício ao trabalho que ora se propõe realizar, à vista do anseio por iniciativas que promovam o aperfeiçoamento da gestão, ao qual seria desejável associar agora uma ação catalisadora e coordenadora.

Entre os fatores motivadores, destacase o desafio de "modernizar a Câmara", apresentado pela Mesa Diretora, particularmente pelo seu Presidente, à nova cúpula administrativa ${ }^{9}$ da Câmara dos Deputados, em 2001. Embora formulado em termos genéricos, esse desafio motivou tal cúpula a buscar mudanças na gestão administrativa, inclusive com relação a alterações na estrutura organizacional. Esse desafio, contudo, tornou mais complexa a necessidade de priorização de necessidades e ações, por sua vez apontada igualmente como fator motivador da construção do planejamento estratégico.
Registram-se, também, como motivadores os chamados fatores isomórficos (REZENDE, 2008), oriundos, sobretudo, da adoção da gestão estratégica em outros órgãos públicos, particularmente no Poder Executivo, a partir de 1995. Em junho de 2004, a Diretoria-Geral (DG) da Câmara criou grupo de trabalho ${ }^{10}$ com a finalidade de avaliar a Câmara segundo os parâmetros apresentados pelo Gespública, programa originado daquele contexto. Esse movimento teve como objetivo identificar marcos e parâmetros adotados pelas instituições públicas que acolhiam conceitos de planejamento estratégico há mais tempo (isomorfismo) e realizar uma avaliação do estado da Câmara em relação a esses marcos e parâmetros. No relatório desse grupo, no item "oportunidades de melhoria", aparece como primeiro tópico: "implantar processo de planejamento estratégico da Câmara".

Outro fator motivador foi a inclusão, pelo órgão de controle (Tribunal de Contas da União), de elementos relacionados à gestão estratégia nos relatórios de prestação de contas $^{11}$. Lane (2001) defende que quanto maior o controle externo, maior - que o usual - é a confiança em normas e regulamentos para o controle interno, com a necessidade de justificativa do comportamento a um órgão externo, criando uma tendência à formalização e ao planejamento.

\section{Histórico analítico}

Em dezembro de 2004 foi realizado um seminário ${ }^{12}$ com a cúpula estratégica ampli$\mathrm{ada}^{13} \mathrm{da}$ área de apoio técnico-administrativo e legislativo, por iniciativa da DG. Nesse seminário foram aprovados a missão, a visão, os valores e os objetivos estratégicos para a área de apoio técnico-administrativo e legislativo. Algumas questões emergiram 
a partir do seminário. Primeiro, a iniciativa de realização do seminário, que foi da DG. Do documento-síntese originado desse Seminário, extrai-se o seguinte trecho:

A Diretoria-Geral da Câmara dos Deputados, com essa iniciativa, vem reafirmar sua crença em que esse modelo de administração há de contribuir para que a Casa desempenhe sempre melhor os seus múltiplos papéis na sociedade e na estrutura do Estado ${ }^{14}$.

No seminário houve também grande discussão quanto à elaboração de um planejamento estratégico para toda a instituição ou apenas para a estrutura técnico-administrativa e legislativa. Optou-se pela última, manifestando-se como razões para tal escolha: a impossibilidade (multiplicidade de estratégias individuais dos parlamentares, bem como dos partidos políticos, em uma leitura inspirada na escola da escolha social, impediria a construção de uma estratégia comum); a impraticabilidade (dificuldades de tempo e logística em reunir 513 parlamentares para discutir o assunto); e a percepção de prescindibilidade (a missão institucional estaria posta pela Constituição Federal, não havendo necessidade de elaboração de uma estratégia) ${ }^{15}$.

Outro fator que fica claro nesse primeiro seminário é a adoção da linha que concebe a estratégia como posicionamento ${ }^{16}$. Segundo essa corrente, a principal tarefa da estratégia é posicionar bem a instituição no seu ambiente competitivo, de forma a maximizar o retorno de longo prazo sobre o investimento. Resguardadas as peculiaridades da Câmara, sobretudo o fato de ser governamental e não lucrativa, trabalhouse com a definição de missão, visão, valores e objetivos, derivada, por sua vez, de análises do tipo SWOT - instrumento típico de planejamento da escola de posicionamento. Essa escolha condiz com a perspectiva de que o planejamento estratégico representa a aplicação da racionalidade ao tratamento de um problema, bem como com a classificação da instituição na tipologia de burocracia mecanizada ${ }^{17}$.

Em 2006 a Diretoria de Recursos Humanos (DRH) desenvolveu seu planejamento estratégico setorial, utilizando a metodologia $\mathrm{BSC}^{18}$. Em dezembro do mesmo ano, foi lançado o Plano de Gestão Estratégica da Área de Recursos Humanos, no qual se apresentou o respectivo Mapa Estratégico Setorial. Posteriormente, outros setores o fizeram (setembro de 2007 - Secretaria de Comunicação Social; dezembro de 2007 - Secretaria de Controle Interno; outubro de 2008 - Diretoria Legislativa; dezembro de 2008 - Diretoria Administrativa). Esse fato levou Botelho e Melo (2009) a considerarem o processo de gestão estratégica da Câmara como "middleup-down" ou "estratégia corporativa deduzida". Entretanto, é importante frisar que a iniciativa do planejamento estratégico foi da DG, em 2004. A escolha do BSC e sua aplicação em um setor (DRH) também teve a aprovação da DG, oficializada em junho de 2007. Esse processo não é raro, sendo, inclusive, previsto pela literatura:

O BSC não funciona como ajustamento imediato a toda a organização, alguns autores sugerem a sua aplicação em zonas selecionadas que tenham alguns fatores favoráveis para que este investimento organizacional tenha maior probabilidade de êxito (Pedro, 2004, p. 16).

A aplicação setorizada do BSC pode ser compreendida como parte do processo de implantação da gestão estratégica na 
Câmara dos Deputados, iniciado em 2004. Tal fato transparece nos textos de apresentação da gestão estratégica, por exemplo:

A partir de 2006, os três macro-objetivos para a gestão da Câmara dos Deputados começaram a ser desdobrados para as áreas funcionais, iniciando pela Diretoria de Recursos Humanos e se desenvolvendo, entre os anos de 2007 e 2008, nos Planejamentos Estratégicos da Diretoria Legislativa, Diretoria Administrativa, Secretaria de Comunicação Social e Secretaria de Controle Interno (CÂmara dos DepuTADOs, Relatório 2007/2008, p. 19).

Portanto, quanto ao processo vivenciado pela Câmara dos Deputados, pode-se afirmar que houve tanto um movimento middle-up-down, com os gestores de nível intermediário, especialmente os que receberam capacitação em conteúdos relacionados à gestão estratégica, exercendo forte influência nos decisores, quanto um movimento top-down, com as principais decisões e momentos originados da Diretoria-Geral, conforme previsto para processos de planejamento estratégico pela tipologia de burocracia mecanizada. Destaque-se, entretanto, que a escolha e a efetiva utilização do BSC trouxe um elemento dinâmico ao planejamento estratégico, permitindo que se começasse a pensar e desenvolver um modelo de gestão estratégica. A elaboração do mapa estratégico, a partir do planejamento estratégico inicialmente realizado, permite que se visualizem elementos objetivos que passam a guiar os processos de mudança (comportamentos e valores). A metodologia BSC é também apropriada para uma burocracia mecanizada, altamente hierarquizada e com grande divisão do trabalho: "compreender a missão e a estratégia é importante para as organizações de especialistas funcionais, que devem alcançar o equilíbrio entre manter a excelência dentro dos silos e, ao mesmo tempo, integrar-se com outras partes da empresa" (Kaplan \& NorTON, 2004, p. 291). Porém, a metodologia do BSC, conforme destacado pelos seus criadores, não é um instrumento de formulação de estratégia, mas sim de tradução da estratégia em medidas operacionais (KAPLAN \& NORTON, 1996, p. 77). Esses autores complementam que a implantação adequada do BSC só é possível em organizações nas quais a estratégia já esteja bem articulada e aceita (KAPlan \& NorTON, 1996, p. 77).

Após elaboração dos mapas estratégicos setoriais, foi constituído um grupo que trabalhou na elaboração do Mapa Estratégico Corporativo. Esse grupo utilizou alguns critérios para identificação dos objetivos que deveriam constar do Mapa Estratégico Corporativo, como: objetivos que apareceram em todos os mapas estratégicos setoriais, objetivos de maior impacto, objetivos interdependentes.

O Mapa Estratégico Corporativo foi lançado em abril de 2009, quando também foram criados o Portal da Estratégia, na intranet, e o Boletim da Estratégia. Em julho de 2009, a Assessoria de Projetos Especiais teve seu nome alterado para Assessoria de Projetos e Gestão, pelo Ato da Mesa $n^{\circ}$ 47, de 7 de julho de 2009. Nas justificativas para a mudança, encontra-se:

A proposta de mudança da nomenclatura Assessoria de Projetos Especiais (Aproj), para Assessoria de Projetos e Gestão (Aproge), reforça as atribuições do órgão no que diz respeito à política de modernização organizacional desta Casa, assessorando diretamente a Diretoria-Geral na 
implantação da Gestão Estratégica, com o objetivo de acompanhar os projetos e programas estratégicos (as novas mudanças) para que se alinhem à missão, visão e valores da Casa (CÂMARA DOs Deputados, 2009).

A designação de um órgão, ligado à DG, para cuidar da implantação da gestão estratégica tem papel importante na integração vertical do planejamento, originariamente processado entre órgãos de diferentes níveis, sendo necessária uma hierarquização harmônica e encadeada.

Em agosto de 2009 houve a primeira Reunião de Avaliação da Estratégia (RAE), a qual viria a se tornar periódica, abrangendo a cúpula administrativa ${ }^{19}$. Nessa RAE foi apresentada a proposta para os primeiros Indicadores Estratégicos Corporativos. Em setembro de 2009, foi constituído grupo de trabalho para homologar e implantar os indicadores estratégicos propostos na primeira RAE. O semestre culminou, em dezembro de 2009, com a realização da segunda RAE, na qual a Mesa Diretora normatizou a gestão estratégica (Ato da Mesa no 56, de 8 de dezembro de 2009). Foi estabelecido o modelo da gestão estratégica, criado o seu selo, e apresentados os primeiros resultados dos Indicadores Estratégicos Corporativos. A normatização da gestão estratégica por ato da Mesa sinalizou a aprovação da área política ${ }^{20}$ ao processo realizado pela área de apoio técnico-administrativo e legislativo, minimizando, de certa forma, a dicotomia "área fim" versus “área meio". Conforme constatado pelas entrevistas, embora a área política não tenha participado efetivamente do processo de planejamento estratégico e implantação da gestão estratégica, essa poderia têlo impedido a qualquer tempo ${ }^{21}$. O então presidente da Câmara dos Deputados, deputado Michel Temer, registrou:

É uma nova estratégia que dá início a uma nova etapa de gestão administrativa, que atende aos pressupostos históricos da modernização do serviço público. Trata-se de agilizar e dar mais eficiência aos trabalhos administrativos e de apoio legislativo. A partir de agora, portanto, passa-se à implantação

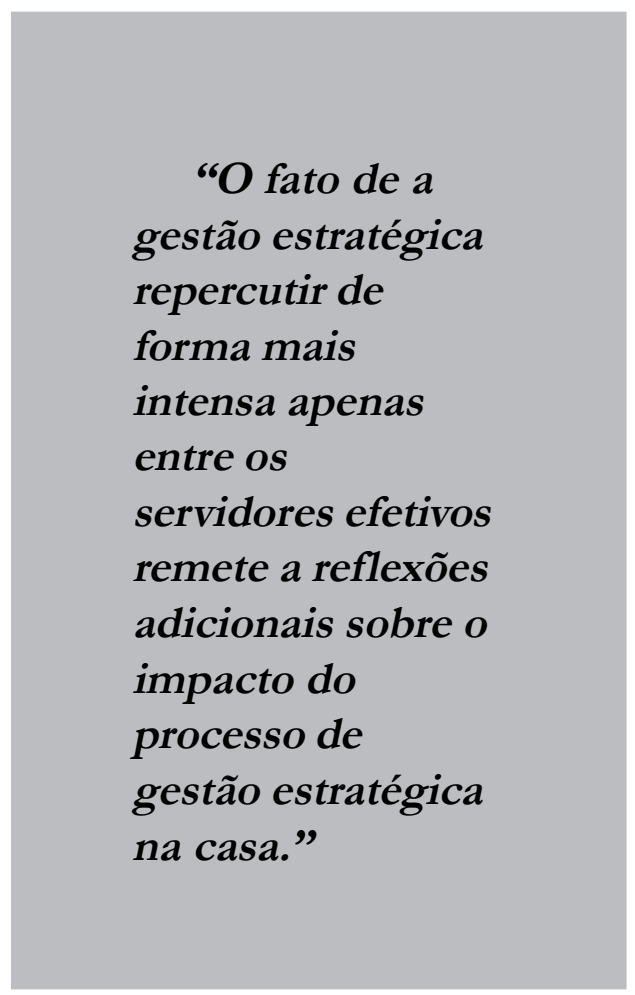

definitiva da Gestão Estratégica, com o apoio da Mesa Diretora (CÂmara dos Deputados, 2009).

O Modelo de Governança da Gestão Estratégica, aprovado em dezembro de 2009, foi apresentado à comunidade em março de 2010, quando também foram formalizados todos os termos de abertura 
dos programas e projetos estruturantes, então em número de dez. Os programas e projetos estruturantes são relacionados a objetivos de base do Mapa Estratégico Corporativo e foram considerados como necessários para que a Câmara pudesse alcançar os objetivos de topo do Mapa. Nesse evento também foi divulgada a criação do Selo da Gestão Estratégica, que passaria a ser afixado nos processos relacionados à gestão estratégica, de modo que esses tramitassem com mais celeridade.

\section{Facilitadores e dificultadores}

Nesta seção, trabalha-se com percepções extraídas das entrevistas, para identificação de fatores que facilitaram ou dificultaram a realização do planejamento estratégico e o processo de sua implantação. Quando se trata de processos de implantação de estratégias deliberadas, são necessárias algumas condições para que a implementação se realize da forma prevista.

Entre os fatores facilitadores, é citada a aprovação da área política, apesar do seu não envolvimento direto na elaboração da estratégia. É relevante a aprovação da área política, consubstanciada em ato da Mesa, uma vez que - embora não se possa dizer que a área política tenha participado do processo - poderia tê-lo impedido ou descontinuado.

Outro facilitador destacado foi o patrocínio da DG, inclusive com a definição de um órgão (Aproge), a ela diretamente subordinado, como responsável pelas questões da gestão estratégica. Circunscrevendo o planejamento estratégico à área de apoio técnico-administrativo e legislativo, conforme já exposto, tem-se na DG o órgão superior na hierarquia da casa. Seu apoio é fundamental para a continuidade do processo. Sintomaticamente, confrontados com a possibilidade de descontinuidade da gestão estratégica em virtude de alterações na composição da Mesa Diretora (órgão político), os entrevistados manifestaram preocupação com uma eventual mudança na DG (órgão administrativo). Bryson (1988), ao tratar de planejamento estratégico em organizações públicas e não lucrativas, destaca como elemento mínimo a existência de apoio por parte de uma autoridade com poder suficiente e a existência de um grupo voltado às questões da gestão estratégica.

Também foi considerado elemento facilitador a alta qualificação dos servidores da Câmara. Para Kaplan e Norton (2004), a disponibilidade de capital humano adequado é um pré-requisito para o que chamam de prontidão estratégica, ou a capacidade da instituição responder rapidamente aos desafios estratégicos e gerar valor a partir dos processos internos.

Finalmente, foi apontado como fator facilitador da implantação da gestão estratégica outro tema relacionado aos servidores: a estabilidade na equipe gestora. $\mathrm{Na}$ Câmara dos Deputados há uma normativa que prevê a ocupação de cargos de chefia exclusivamente por servidores efetivos (concursados), diferentemente de outros órgãos públicos brasileiros. Essa restrição produz, na visão dos entrevistados, maior estabilidade dos gestores nos cargos de chefia, o que, por sua vez, tem como consequência menor risco de descontinuidade das ações.

Entre os elementos que dificultaram o processo de implantação da gestão estratégica aponta-se, inicialmente, uma resistência ao tema, amparada na percepção de sua prescindibilidade. Esse ponto de vista, por sua vez, fundamenta-se em duas argumentações. A primeira relaciona-se à visão de que o papel e a missão da Câmara dos Deputados seriam óbvios e já estariam 
inteiramente demarcados na Constituição Federal. Associada a essa percepção, está o conceito de que a Câmara é um monopólio (exclusividade da prerrogativa de legislar em nível federal), o que torna a preocupação com estratégia e concorrência irrelevante ${ }^{22}$. A segunda concerne ao perfil de uma burocracia mecanizada, com sua administração burocrática-racional, de perfil weberiano. Caracterizada por estrutura administrativa muito elaborada, fluxo de trabalho altamente racionalizado, tarefas operacionais simples e repetitivas e ênfase na padronização dos processos de trabalho, a burocracia mecanizada é fortemente voltada para gerar resultados. Nesse tipo de ambiente, a estratégia pode ser percebida como desnecessária - basta que o serviço, predefinido institucionalmente, seja feito. Além da resistência inicial, essas percepções podem ser explicativas de outros fatores, apontados como dificultadores: reduzido número de servidores envolvidos, baixo envolvimento dos gerentes intermediários, participação desigual entre áreas e setores.

Os dificultadores relacionados a pessoas coadunam-se ao que Kaplan e Norton (2004) qualificam como prontidão do capital organizacional, ou a "capacidade da organização de mobilizar e sustentar o processo de mudança necessário para executar a estratégia" (KAPLAN \& NORTON, 2004, p. 281). Entre os elementos da prontidão do capital organizacional, esses autores destacam a cultura (consciência e internalização da missão, visão e valores essenciais à execução da estratégia); a liderança (disponibilidade de líderes qualificados, em todos os níveis); o alinhamento (interligação dos objetivos e dos incentivos individuais, de equipes e departamentos); e o trabalho em equipe (compartilhamento do conhecimento com potencial estratégico). Ainda segundo esses autores, a prontidão do capital organizacional torna-se mais importante em instituições historicamente orientadas para dentro e altamente reguladas, como é o caso da área de apoio técnicoadministrativo e legislativo da Câmara dos Deputados.

Outro fator apontado como complicador para a implantação da gestão estratégica na Câmara dos Deputados é a heterogeneidade de sua força de trabalho. São aproximadamente 3.400 servidores efetivos, 1.200 ocupantes de cargos de natureza especial (CNE), cerca de 11 mil secretários parlamentares, além dos 513 deputados. Os CNE e os secretários parlamentares vinculam-se diretamente aos parlamentares (contratação e demissão ad nutum), o que traz características patrimonialistas à relação. Em sistemas patrimonialistas, sob a ótica dos servidores, têm primazia os interesses dos seus respectivos contratantes, conforme argumentado por Weber (2000), o que torna mais complexa a implantação de uma gestão estratégica. Outras experiências de implantação do BSC em instituições públicas também revelaram como dificuldade a heterogeneidade da força de trabalho, conforme Johnson (1999, p. 13): “a força de trabalho complexa e diversificada do ministério e suas regras de remuneração fazem com que o desdobramento do BSC para o nível individual nunca possa ser apropriado" ${ }^{23}$. O fato de a gestão estratégica repercutir de forma mais intensa apenas entre os servidores efetivos remete a reflexões adicionais sobre o impacto do processo de gestão estratégica na casa.

Aponta-se a ausência de sistema informatizado, para acompanhamento da gestão estratégica, como empecilho ao processo. Kaplan e Norton (2004) chamam esse fator de prontidão do capital 
da informação: "a prontidão estratégica do capital da informação mede a extensão em que o capital da informação respalda a estratégia da empresa" (KAPLAN \& NorTON, 2004, p. 269).

Os entrevistados também expuseram - como dificultadores - fatores de ordem cultural, como resistência à mudança e falta de cultura de gestão por resultados ${ }^{24}$, com as respectivas cobranças. Para Kaplan e Norton (2004), esses fatores podem se referir tanto ao clima organizacional "conjunto de influências da organização sobre a motivação e o comportamento dos empregados" (KAPLAN \& NorTON, 2004, p. 292) - quanto à cultura propriamente dita - "identifica os símbolos, os mitos, as histórias e os rituais impregnados na consciência (ou subconsciência) da organização. A cultura tenta captar os sistemas de significados compartilhados, premissas e valores da organização" (KAPLAN \& NorTON, 2004, p. 293). Na dimensão do clima organizacional, mais afeita à área da psicologia social, são trabalhadas dimensões como a estrutura organizacional, o sistema de recompensas, a percepção do zelo e apoio transmitidos pelos superiores e pares. Na dimensão da cultura organizacional, podem ser trabalhadas dimensões como predisposição para inovação e tomada de riscos, atenção a detalhes, nível de agressividade e competitividade, grau de solidariedade, percepção de possibilidades de crescimento e recompensas, colaboração e trabalho em equipe, assertividade e orientação para resultados.

De várias formas, esses fatores foram mencionados pelos entrevistados como dificultadores. O indivíduo orienta sua ação pela situação, reunindo, para tanto, suas expectativas e sua análise subjetiva quanto à causalidade entre fins e meios e quanto às probabilidades de sucesso. O clima organizacional e a cultura são fatores determinantes das circunstâncias e dos contextos (mundo dado) e restringentes do mundo ideal (almejado pela visão estratégica). A partir do que é dado (ou considerado como tal) e das suas possibilidades objetivas inerentes, o indivíduo vai avaliar se os meios são apropriados para se conseguir a pretendida transformação da realidade, no caso, o atingimento dos objetivos estratégicos propostos.

\section{Resultados iniciais e desafios futuros}

Percebe-se, com a implantação da gestão estratégica, uma identificação mais clara das ações prioritárias, com rebatimento direto no processo decisório. Exemplar dessa percepção foi o estabelecimento de prioridades para desenvolvimento de soluções de tecnologia de informação e comunicação, que levou em consideração as necessidades mais prementes apontadas pelo Mapa Estratégico Corporativo. De sua parte, o Centro de Informática percebe que esse processo de priorização possibilitou melhora qualitativa na prestação de serviços.

Outro fator destacado foi a realização "impositiva" de reuniões entre os integrantes da cúpula administrativa - as RAE. Conforme já argumentado, em uma instituição com as características de uma burocracia mecanizada, a tendência à exacerbação do isolamento entre os setores é grande. A obrigatoriedade de realização de reuniões, com enfoque nas questões do planejamento estratégico, exerce grande efeito de coordenação entre as áreas.

A escolha da metodologia de BSC leva, consequentemente, à criação de indicadores, os quais permitem um panorama do que está acontecendo, além da possibilidade objetiva de cobrança. Em uma 
instituição na qual inexiste a cultura de gestão por resultados e cobrança (ver tópico anterior), esse é um fator positivo. Como esses indicadores ainda estão sendo construídos, propostos e implementados, entretanto, permanece como desafio sua definição e acompanhamento.

As entrevistas revelam a percepção, como carência, de uma necessidade de consolidação do ambiente da gestão estratégica. Sob essa percepção, destacam-se questões como a maior vinculação do processo decisório ao planejamento estratégico realizado (persistência de decisões que não levam em consideração o Mapa Estratégico Corporativo); a necessidade de adaptação da estrutura organizacional para contemplar a gestão por projetos e a gestão por processos; a maior autonomia da área de apoio técnico-administrativo e legislativo para tomada de decisões, desde que previstas no planejamento estratégico realizado.

Também se percebe como desafio a vinculação do orçamento institucional à estratégia (uma das propostas da administração pública gerencial), o que, no caso de uma instituição complexa como a Câmara dos Deputados, é difícil. Outra vinculação necessária seria da política remuneratória à gestão estratégica, como, inclusive, fator de rompimento da inércia causada por fatores culturais; o que não seria simples, contudo, tendo em vista tratar-se de instituição regida por normas rígidas referentes à remuneração, que requerem, inclusive, a previsão legal para serem levadas a cabo.

\section{Considerações finais}

A implantação da gestão estratégica na Câmara dos Deputados é um processo complexo e multifacetado. As características de órgão público, hierarquizado, com alta divisão de trabalho (burocracia mecanizada), fazem com que seu processo de planejamento ocorra segundo determinadas formas, as quais se confirmam pelo confronto do tipo com a literatura da área.

Entretanto, algumas de suas peculiaridades (casa política, com 513 parlamentares) trazem elementos novos e desafiadores ao processo, como a decisão de realizar um planejamento exclusivo para a área de

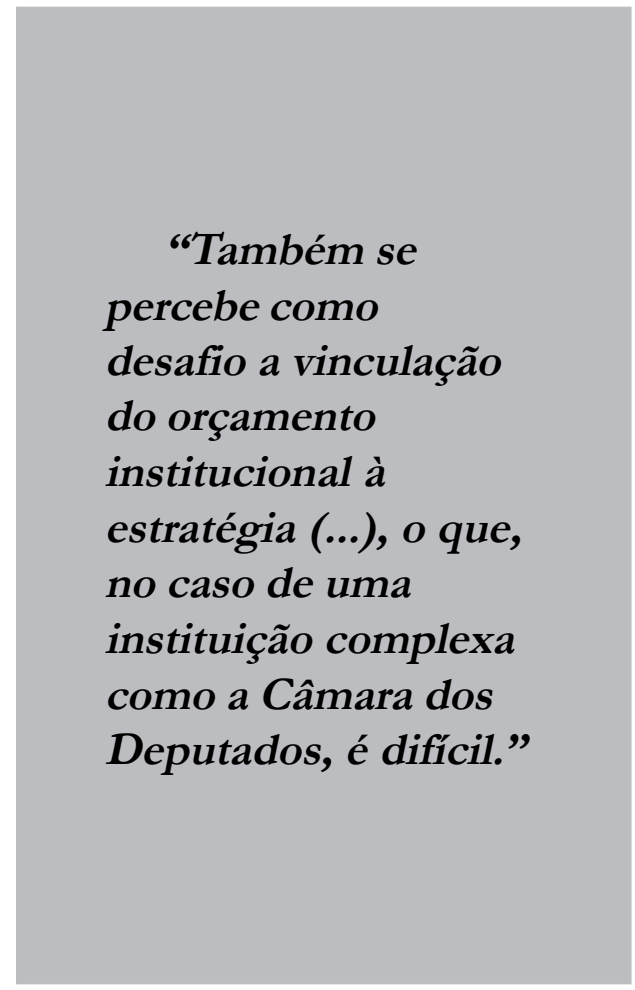

apoio técnico-administrativo e legislativo. Se fosse uma empresa, poder-se-ia dizer que foi realizado um "planejamento estratégico para a área meio", sem envolver a "área fim”, o que seria um paradoxo. Resguardadas as particularidades da Câmara dos Deputados e os fatores apontados como justificadores dessa escolha (impossibilidade, impraticabilidade, prescindibilidade), observa-se um 
elemento estratégico quando se propõe como visão "ser modelo de excelência na administração pública”. Pela ótica de Porter (1999), pode-se argumentar que ser "modelo de excelência” é ocupar uma posição exclusiva e diferenciada, portanto, estratégica. No caso, considerando-se estritamente a área de apoio técnico-administrativo e legislativo, essa escolha é apropriada, pois seus "concorrentes" (diante dos quais teria que ter uma posição exclusiva e diferenciada) seriam o corpo técnico-administrativo de outros órgãos públicos. Contudo, a relação dos objetivos estratégicos, o Mapa Estratégico Corporativo, e os dados colhidos das entrevistas não permitem afirmar com certeza que se trabalha com a perspectiva estratégica, interpretando-se a proposição de Porter (1999) de uma forma mais radical. Antes, seria um processo de melhoria operacional.

O processo avança lentamente (iniciado em 2004 e ainda não consolidado), devido aos elementos dificultadores apontados, sobretudo os de ordem cultural. Acostumados a um ambiente fundado na regularidade dos procedimentos (controle do ato e do processo), na estabilidade das estruturas formais, na hierarquia e na primazia dos meios, os servidores encontram dificuldades para se adaptarem a uma realidade que valoriza a eficácia (controle dos resultados), a flexibilidade, a delegação de poder e a negociação, com a primazia dos fins.

Para não exibir uma perspectiva excessivamente otimista, reconhece-se que qualquer pesquisador que se defronte com uma instituição do Poder Legislativo, no cenário brasileiro atual, vai encontrar ainda uma burocracia mecanizada. Porém, caso se proponha a investigar mais a fundo, poderá enxergar experiências iniciais de mudança, como as levantadas junto à
CD. A administração pública legislativa confronta-se com a necessidade de alcançar o interesse público ${ }^{25}$ nela depositado, em um mundo de fatos contingentes. O administrador público legislativo está sujeito a dinâmicas e manifestações de diversas naturezas (econômica, política, ideológica, antropológica, psicológica, filosófica ou gerencial), e, portanto, deve acatar condições de flexibilidade para seu agir $^{26}$. Como o interesse público é considerado dado, a administração pública legislativa focaliza os fatos. Desses, alguns são concretos, e dizem respeito a como as coisas são, outros são probabilísticos, relacionando-se a como as coisas deveriam ser. A gestão estratégica aplicada à administração pública legislativa deve criar uma moldura desejável para esse devir, bem como prescrever caminhos para que as instituições do Poder Legislativo possam se conformar à paisagem almejada.

Uma das constatações, e motivações, do artigo é a escassez de literatura sobre o tema da gestão estratégica em órgãos do Poder Legislativo, o que pode sinalizar escassez de experiências de gestão estratégica por parte de tais organismos, em seus diferentes níveis. A agenda de pesquisa segue com a proposta de realizar levantamentos comparativos sobre gestão estratégica em órgãos do Poder Legislativo, o que poderá trazer novos elementos para uma avaliação mais abrangente do caso.

Percebe-se, todavia, que a experiência da Câmara dos Deputados traz elementos relevantes para o fenômeno da gestão estratégica no setor público, seja por apresentar o processo de sua implementação, de forma analítica e confrontada com a teoria, seja por tratar especificamente de um órgão do Poder Legislativo.

(Artigo recebido em outubro de 2011. Versão final em fevereiro de 2012). 


\section{Notas}

${ }^{1}$ A pesquisa documental foi realizada em normas oficiais (Atos Administrativos, Resoluções) e documentos de registro histórico do processo de elaboração e implantação da Gestão Estratégica da Câmara dos Deputados, disponíveis em sua página na internet (http:// www.camara.gov.br/).

${ }^{2}$ Foram 10 entrevistas. Todos os entrevistados assinaram Termo de Consentimento Livre e Esclarecido, no qual os autores assumiram o compromisso de manter as entrevistas confidenciais, uma vez que uma das suas propostas era identificar elementos de bastidores do processo.

${ }^{3}$ As tipologias propostas por Mintzberg (2003) são: estrutura simples, burocracia mecanizada, burocracia profissional, forma divisionalizada e adhocracia.

${ }^{4} \mathrm{O}$ termo New Public Management, que vem sendo traduzido no Brasil como administração pública gerencial, surgiu na literatura acadêmica no princípio dos anos 1990 e refere-se, de uma forma geral, a temas, estilos e padrões de gestão do serviço público, associados a reflexões sobre melhoria e modernização da administração pública, conforme Barzelay (2001).

${ }^{5}$ Criada pela Resolução da Câmara dos Deputados no $32 / 2002$.

${ }^{6}$ Grupo formalizado pela Portaria do Diretor-Geral no 129 , de 21/11/2003.

${ }^{7} \mathrm{O}$ planejamento estratégico da Consultoria Legislativa, feito nessa época, nem chegou a ser implantado. O do Centro de Informática foi implantado, porém sempre com uma perspectiva autocêntrica.

${ }^{8}$ Disponível em: «www.camara.gov.br». Acessado em: 14/04/2011.

${ }^{9}$ No âmbito deste artigo, cúpula administrativa significa o diretor-geral (FC10), o diretor administrativo (FC9), o diretor legislativo (FC9) e o diretor de Recursos Humanos (FC9).

${ }^{10}$ GT instituído pela Portaria do diretor-geral no $76 / 2004$.

${ }^{11}$ A Instrução Normativa do TCU no 57/2008 ampliou o conceito de processo de contas, dando ênfase à questão do desempenho, especificamente quanto à produção de resultados pelo aparato estatal.

${ }^{12}$ De caráter imersivo, dois dias de reunião em local fora da Câmara dos Deputados, com a colaboração de consultores externos, a título de facilitadores.

${ }^{13}$ Diretor-geral, diretor legislativo, diretor administrativo, diretor de Recursos Humanos e diretores de Departamentos e Centros. Na estrutura administrativa da Câmara dos Deputados, o diretor-geral ocupa uma função comissionada FC10, os diretores legislativo, administrativo e de Recursos Humanos ocupam função comissionada FC9, e demais diretores FC8. Também havia a presença de chefes de gabinete de lideranças partidárias (FC8). Estima-se em sessenta a quantidade de participantes nesse seminário.

${ }^{14}$ Diretrizes estratégicas para a gestão da Câmara dos Deputados. Disponível em: «www.camara.gov.br». Acessado em: 14/04/2011.

${ }^{15}$ Embora a decisão tenha sido tomada e o processo esteja em curso de implantação, há elementos controversos quanto a essa decisão, que não serão explorados no presente artigo.

${ }^{16}$ Mintzberg (1994), analisando as teorias existentes sobre estratégia, encontra duas visões teóricas predominantes: a que assume a estratégia como problema de posicionamento e a que a assume como uma questão de perspectiva.

${ }^{17}$ Cf. Mintzberg (2003). 
${ }^{18}$ Houve, em maio de 2006, um processo de capacitação de servidores para a utilização do BSC, o que também foi considerado ponto importante para a decisão quanto à utilização dessa metodologia.

${ }^{19}$ Participam da RAE, ordinariamente, os membros do Comitê de Gestão Estratégica, a saber: diretor-geral, secretário-geral da Mesa, diretor de Recursos Humanos, diretor administrativo, diretor legislativo, secretário de Comunicação Social, secretário de Controle Interno e diretor da Assessoria de Projetos e Gestão.

${ }^{20}$ No âmbito desse artigo, quando se refere à área "política", refere-se estritamente aos parlamentares.

${ }^{21}$ A Mesa Diretora exerce, perante a área de apoio técnico-administrativo e legislativo da Câmara dos Deputados, papeis similares ao de um Conselho de Administração, perante os executivos de uma empresa privada. Ao primeiro-secretário da Mesa são atribuídas explicitamente competências quanto a decisões sobre administração da Câmara dos Deputados.

${ }^{22}$ Visão do órgão público como monopólio exposta por Moore (1997, p. 70).

23 "the ministry's complex and diverse workforce and its remuneration rules mean that cascading the BSC to the individual level may never be appropriate", tradução dos autores.

${ }^{24}$ Além da falta de cultura de gestão por resultados, destaca-se que o Direito Administrativo brasileiro (arcabouço normativo no âmbito do qual operam os servidores públicos), pós Constituição de 1988, rege-se por uma ótica da desconfiança no Estado, com ênfase para o controle dos atos e dos processos, e não dos resultados.

${ }^{25}$ Há os que prefiram falar em valor público. De qualquer modo, trata-se de conceito sempre sujeito a controvérsias quanto à possibilidade de sua identificação e, consequentemente, mensuração. A menção ao interesse público, contudo, não pretende aqui inserir elementos metafísicos à discussão, mas constatar que ele existe. Procede-se em sintonia com o pensamento de Tullock: "there is an 'ought' somewhere in the organizational structure, even if only in the dreams of the organizer. Looked at from the outside, this 'ought' provides the only justification for the existence of the structure at all" (Tullock, 2004, p. 127).

${ }^{26}$ Essa flexibilidade no agir deverá ser acompanhada, necessariamente, de flexibilidade nos controles, assunto que não é objeto de discussão neste trabalho.

\section{Referências bibliográficas}

BARZELAY, Michael. The new public management - improving research and policy dialogue. The University of California Press, 2001.

Bauer, Martin W.; Gaskel, George. Pesquisa qualitativa com texto, imagem e som: um manual. $7^{\mathrm{a}}$ ed. Petrópolis, RJ: Vozes, 2008.

Besanko, David et al. A economia da estratégia. Porto Alegre: Bookman, 2006.

Botelho, Cássia R. O. M.; Melo, Maria Raquel Mesquita. Planejamento e Gestão Estratégica na Câmara dos Deputados: Quebrando Paradigmas. Disponível em: http:/ / www.consad.org.br/sites/1500/1504/00001329.pdf. Acessado em: 15 fev. 2011. 
Brasil. Presidência da República. Plano Diretor da Reforma do Aparelho do Estado. Brasília, 1995.

BRYSON, John M. A strategic planning process for public and non-profit organizations. Long Range Planning, v. 21, $\mathrm{n}^{\circ}$ 1, p. 73-81, 1988, Inglaterra.

CÂmara dos Deputados. Relatório 2007/2008, v. 2. Brasília: Edições Câmara, 2008.

CÂmara dos Deputados. Boletim da Gestão Estratégica, no 01, 16 abr. 2009.

CÂmara dos Deputados. Ato da Mesa nº 47, Brasília, DF, 7 jul. 2009.

Copeland, Gary W.; Patterson, Samuel C. Parliaments in the modern world: changing institutions. Michigan, USA: The University of Michigan Press, 1997.

FAYOL, Henry. Administração industrial e geral: previsão, organização, comando, coordenação, controle. São Paulo: Atlas, 2010.

Johnson, Lauren Keller. Making Strategy a Continual Process at the U.K. Ministry of Defence. Boston: Harvard Business Publishing, 1999.

KAPLAN, Robert S.; NorTON, David P. A execução premium: a obtenção de vantagem competitiva através do vínculo da estratégia com as operações do negócio. Rio de Janeiro: Elsevier, 2008.

Alinhamento: usando o Balanced Scorecard para criar sinergias corporativas. Rio de Janeiro: Elsevier, 2006.

Linking the Balanced Scorecard to Strategy. California Management Review; Fall 1996; 39, 1; ABI/INFORM Global, p. 53.

. Mapas estratégicos - Balanced Scorecard: convertendo ativos intangíveis em resultados tangíveis. Rio de Janeiro: Elsevier, 2004.

Lane, Jan-Erik. New Public Management. Londres: Routledge, 2001.

MintzBerg, Henry. Criando organizações eficaz̧es: estruturas em cinco configurações. $2^{\mathrm{a}}$. ed. São Paulo: Atlas, 2003.

Safári de estratégia: um roteiro pela selva do planejamento estratégico. Porto Alegre: Bookman, 2010. The rise and fall of strategic planning. USA:The Free Press, 1994.

Moore, Mark H. Creating Public V alue: strategic management in government. Cambridge, Massachusetts: Harvard University Press, 1997.

Osborne, David; Gaebler, Ted. Reinventando o governo - como o espirito empreendedor está transformando o setor público. $8^{\mathrm{a}}$ ed. Brasília: MH Comunicação, 1995.

Pedro, José Maria. O Balanced Scorecard (BSC) no Sector Publico. Informação e Informática. Revista das Tecnologias da Informação na Administração Pública, no 28, 2004, p. 14 a 23.

Porter, M. E. Estratégia Competitiva. Rio de Janeiro: Campus, 1986.

Competição: estratégias competitivas essenciais. Rio de Janeiro: Campus, 1999.

Como as forças competitivas moldam a estratégia. In: PORTER, M. E.

Competição: estratégias competitivas essenciais. Rio de Janeiro: Campus, 1999a. 
O que é estratégia? In: PORTER, M. E. Competição: estratégias competitivas essenciais. Rio de Janeiro: Campus, 1999b.

Porter, M. E. Vantagem competitiva. Rio de Janeiro: Campus, 1989.

Rezende, Flávio da Cunha. The implementation problem of new public management reforms: the dilemma of control and the theory of sequential failure. International Public Management Review, v. 9, Issue 2, 2008. http:/ / www.ipmr.net.

TAYLOR, Frederick Winslow. Princípios de administração científica. São Paulo: Atlas, 2010.

Tullock, Gordon. The politics of bureaucracy. Washington, DC: Public Affairs Press, 2004.

Weber, Max. Economia e sociedade: fundamentos da sociologia compreensiva. Brasília: Editora Universidade de Brasília, 2000. 


\section{Resumo - Resumen - Abstract}

Gestão estratégica no Poder Legislativo: o caso da Câmara dos Deputados

André Sathler Guimarães, Fabiano Peruzzo Schwartz, Juliana Werneck. de Souza, Maria Raquel Mesquita Melo e Rogério Ventura Teixeira

O objetivo do artigo é registrar o processo de implantação da gestão estratégica na Câmara dos Deputados, com o propósito de revelar seus antecedentes e motivações, os momentoschave, as facilidades e dificuldades, os resultados alcançados e os desafios futuros. A abordagem escolhida foi a histórico-descritiva, e as ações de pesquisa envolveram revisão bibliográfica, pesquisa documental e entrevistas semiestruturadas. As conclusões apontam que a implantação da gestão estratégica na Câmara dos Deputados é um processo complexo e multifacetado, diante de suas características de órgão público, hierarquizado, com alta divisão de trabalho. $\mathrm{O}$ avanço da implantação é lento, devido aos fatores dificultadores observados. O caso traz elementos relevantes para a pesquisa sobre gestão estratégica no setor público, seja por apresentar o processo de forma analítica e confrontada com a teoria, seja por se tratar especificamente de um órgão do Poder Legislativo.

Palavras-chave: Administração Pública. Gestão Estratégica. Câmara dos Deputados. Balanced scorecard.

Gestión estratégica en el Poder Legislativo: el caso del Congreso de los Diputados André Sathler Guimarães, Fabiano Peruzzo Schwartz, Juliana Werneck de Souza, Maria Raquel Mesquita Melo y Rogério Ventura Teixeira

El objetivo de este trabajo es registrar, de manera crítica, el proceso de implementación de la gestión estratégica en el Congreso de los Diputados, a fin de revelar su origen y las motivaciones, los momentos clave, las facilidades y dificultades, logros y retos pendientes. El método seleccionado fue el histórico-descriptivo, y las actividades de investigación con revisión de la literatura, la investigación de archivo y entrevistas semiestructuradas. Los resultados indican que la aplicación de la gestión estratégica en el Congreso de los Diputados es un proceso complejo y polifacético, considerándose las características de un organismo público, y la grande división jerárquica del trabajo. El progreso de la implementación es lento debido a los mencionados factores que imponen dificultades. El caso tiene elementos relevantes para la investigación sobre la gestión estratégica en el sector público, ya sea por presentar el proceso analítico en comparación con la teoría, ya sea por tratarse específicamente de un órgano del poder Legislativo.

Palabras clave: Administración Pública. Gestión Estratégica. Congreso de los Diputados. Balanced scorecard.

\section{Strategic Management: the case of the Brazilian Chamber of Deputies}

André Sathler Guimarães, Fabiano Peruгzo Schwartz, Juliana Werneck de Souza, Maria Raquel Mesquita Melo and Rogério Ventura Teixeira

This paper aims to discuss the implementation process of strategic management at the Brazilian Chamber of Deputies, in order to reveal their backgrounds and motivations, the key moments, achievements and future challenges. The research approach chosen was historicaldescriptive. Research activities included literature review, documental research and qualitative interviews. The findings indicate that the implementation of strategic management in the Chamber of Deputies is a complex and multifaceted process, due its characteristics of a public institution, 
highly hierarchized and with a pronounced division of labor. There is a slow progress of the process, due to the nature of the Chamber of Deputies. The case has relevant elements to research on strategic management in public sector, by presenting the process analytically and compared with theory, and by focusing the Legislative Power.

Keywords: Public Management. Strategic Management. House of Representatives. Balanced scorecard.

\section{André Sathler Guimarães}

Doutor em Filosofia pela Universidade Federal de São Carlos (UFSCar), mestre em Comunicação pela Universidade Metodista de São Paulo, mestre em Gerenciamento de Sistemas de Informação pela Pontifícia Universidade Católica de Campinas (PUC-Campinas) e graduado em Ciências Econômicas pela Universidade Federal de Minas Gerias (UFMG). É Analista Legislativo na Câmara dos Deputados. Contato: andre.sathler@camara.gov.br

\section{Fabiano Peruzzo Schwartz}

Doutor em Engenharia de Sistemas Eletrônicos e de Automação pela Universidade de Brasília (UnB), mestre em Ciência da Computação (UnB), graduado em Engenharia Elétrica (UnB) e Tecnólogo em Processamento de Dados pela Universidade Católica de Brasília (UCB). É Analista Legislativo na Câmara dos Deputados. Contato: fabiano.schwartz@camara.gov.br

\section{Juliana Werneck de Souza}

Especialista em Desenvolvimento Gerencial pela Universidade de Brasília (UnB), especialista em Educação aplicada ao contexto das organizações pelo Instituto de Educação Superior de Brasília (IESB) e graduada em Enfermagem e Obstetrícia pela (UnB).É Analista Legislativo na Câmara dos Deputados. Contato: juliana.souza@camara.gov.br

Maria Raquel Mesquita Melo

Especialista em Organização, Sistemas e Métodos pela Escola Brasileira de Administração Pública do Distrito Federal (FGV/EBAP-DF) e graduada em Processamento de Dados pela Universidade de Brasília (UnB). Analista Legislativo na Câmara dos Deputados. Contato: raquel.melo@camara.gov.br

\section{Rogério Ventura Teixeira}

Mestre em Gestão Social e Trabalho pela Universidade de Brasília (UnB), especialista em Desenvolvimento Gerencial (UnB), Especialista em Planejamento e Administração de Recursos Humanos pela Associação de Ensino Unificado do Distrito Federal (UDF) e graduado em Administração pela (UDF). É Diretor-Geral da Câmara dos Deputados. Contato: rogerio.teixeira@camara.gov.br 